\title{
Sorptive behaviour of chromium on polyethylene microbeads in artificial seawater
}

\author{
Nur Farhan Zon ${ }^{1}$, Ammar Iskendar ${ }^{1}$, Shamila Azman ${ }^{1, *}$, Shazani Sarijan ${ }^{1}$, and Razali \\ Ismail $^{2}$ \\ ${ }^{1}$ Department of Water and Environmental Engineering, School of Civil Engineering, Faculty of \\ Engineering, Universiti Teknologi Malaysia, 81310 Johor Bahru, Johor, Malaysia \\ ${ }^{2}$ Department of Chemistry, Faculty of Science, Universiti Teknologi Malaysia, 81310 Johor Bahru, \\ Johor, Malaysia
}

\begin{abstract}
This study investigates the interactions between chromium $(\mathrm{Cr})$ and microplastic under controlled laboratory conditions using low density polyethylene microbeads as plastic particles. Chromium was added to suspensions of in artificial seawater to investigate heavy metal adsorption on microbeads surface. Polyethylene microbeads proved to have affinity in providing surface area for chromium. It served as an effective sorption surface thus lowering amounts of chromium in seawater through adsorption process. The best percentage of heavy metals adsorbed to microbeads and adsorption capacity was $1.7 \mu \mathrm{g} / \mathrm{g}$ and $8.5 \%$ at $1.0 \mu \mathrm{g} / \mathrm{mL}$ respectively. The maximum adsorption was monitored for 180 hours. Kinetic study was performed and fitted well in pseudo-first-order kinetic. In term of isotherm, dataset was in good agreement with both Langmuir and Freundlich with correlation at 0.977 and 0.9606 respectively. Adsorption of chromium to polyethylene microbeads had important implications for the potential role of microplastics, in this case microbeadschromium contaminated act as a quantified link in aquatic food webs.
\end{abstract}

\section{Introduction}

Microplastic is plastic smaller than $5 \mathrm{~mm}$, whether intentionally manufactured to be that size or as a result of fragmentation and breakdown of larger plastic products which is now abundant within our aquatic environment. Alarming numbers of microplastic have been found within sediments of estuaries, freshwater and intertidal or coastal ecosystems [1-4]. Microplastic cause negative impact to the environment due to their small size and ability to carry contaminants, thus eventually effects the aquatic life through ingestion [8-13].

The interaction of microplastic to metals became primary concerned in marine ecosystem in current research. Holmes and colleagues concluded that addressing metal $(\mathrm{Cr}$, $\mathrm{Co}, \mathrm{Ni}, \mathrm{Cu}, \mathrm{Zn}, \mathrm{Cd}$ and $\mathrm{Pb}$ ) sorption kinetics to virgin and beached polyethylene pellets could reach equilibrium within 25 to $100 \mathrm{~h}$ [14]. While, Brennecke and co-workers studied the interaction between two types of known polymers (virgin polystyrene plastic beads; PS and aged polyvinylchloride fragments; PVC) with heavy metals (antifouling paint). The

\footnotetext{
* Corresponding author: shamila@utm.my
} 
study was performed by exposing different types of microplastics to heavy metal pollution under controlled laboratory conditions and mimicked anthropogenic environment [15].

Microbeads are intentionally manufactured microplastic that are used in cosmetic and personal care product which contributed to occurrence of microplastic in environment. The beauty manufactures products that people use daily containing microplastic and used as abrasives marketed as "microbeads." Microbeads are virtually indestructible, often perfectly spherical, multi-coloured, buoyant, and typically much smaller than $5 \mathrm{~mm}$ making them quite distinct from other plastic found in the environment $[5,6]$. Once a product containing microbeads is washed off a person's hands or face, the cleaning agents plus the microbeads are rinsed down the drain and will enter wastewater systems. The products contained microbeads were usually disposed into municipal sewer systems without proper treatment. Because of their small size and buoyancy, many microbeads escape from filtration by wastewater treatment plants. Subsequently, microbeads in the treated water are discharged to rivers, lakes, or oceans, where they accumulate and persist [7].

The study of microbeads ability to sorb the contaminants from cosmetic and personal care products is scarce. Boucher and colleagues reported the microcosm study for microbeads from cosmetic cleanser [9]. It was suggested that, the microbeads provided sorption sites for lead $(\mathrm{Pb})$ and cadmium $(\mathrm{Cd})$ within intertidal sediments. This ability could be considered as an action of vector for heavy metals to enter the food chain with ingested microbeads [3]. Hence, the purpose of this study is to assess the interactions between heavy metals and microbeads under controlled laboratory condition. Using polyethylene microbeads as plastic particles, the sorptive ability of polyethylene microbeads for different concentration of chromium were evaluated by kinetic and isotherm study.

\section{Materials and Methods}

The experiment was performed in order to investigates the interactions between chromium and polyethylene microbeads under controlled laboratory conditions using virgin polyethylene microbeads as plastic model.

\subsection{Chemicals and apparatus}

Milli-Q deionized (18.2 M 2 ) water, was used in all experimental work. Polyethylene microbeads with size $200 \mu \mathrm{m}$ was obtained from a local plastic company. Instant Ocean synthetic sea salt (Aquarium Systems Inc., Sarreboug, France) was used to prepare artificial sea water (ASW). Analytical grade, concentrated nitric acid (Merck 98\% and 65\%) was used throughout the study. Stock solution of Cr (Perkin Elmer, USA) were prepared from $1000 \mu \mathrm{g} / \mathrm{mL}$ by several step dilution. All experimental apparatus such as glass tank, volumetric flask, beakers, syringes, and bottle samples were soaked for 24 hours in diluted nitric acid $(10 \%)$ and later double-rinsed with deionized water to avoid possible contamination.

\subsection{Sorptive study of polyethylene microbeads}

Batch experiments were conducted for heavy metals $\mathrm{Cr}$ with 3 different concentrations added to 1 litre artificial seawater in order to produce $0.2,0.6$ and $1.0 \mu \mathrm{g} / \mathrm{ml}$ solution. The sorptive test was conducted for 180 hours with aeration. Seawater and microbeads were then sampled by recovering $30 \mathrm{~mL}$ of water and approximately $1 \mathrm{~g}$ of microbeads at 12 hours subsequently. The batch tank was observed frequently to maintain its original 
condition. Samples was then placed into $10 \mathrm{~mL}$ test tubes and preserved. The experiment was repeated in triplicates.

\subsection{Microwave acid digestion for polyethylene microbeads}

Samples were weighted at $300 \mathrm{mg}$ and mixed together with $6 \mathrm{~mL}$ of $65 \%$ of nitric acid. Samples were then placed in oven vessel, capped and put in digestor (Milestones SK-10, USA) and heated at $110^{\circ} \mathrm{C}$ for 4 minutes. Then, the sampled was cooled in ice-cold water for 15 minutes and heated again at $200^{\circ} \mathrm{C}$. The resulting solution was diluted to $25 \mathrm{~mL}$ in volumetric flask and filtered. Sample solution then analysed with atomic absorption spectrophotometer (Perkin Elmer PinAAcle 900T).

\section{Results and Discussion}

In this study, it was proven that chromium was able to be adsorbed onto microbeads surface. Results obtained are shown as percentage of adsorption and adsorption capacity of polyethylene microbeads versus initial concentration of chromium in Figure 1. There is different in ability of microbeads adsorption with respect to initial concentration. For instance, chromium show $6.5 \%$ to $8.5 \%$ adsorption at $0.2 \mu \mathrm{g} / \mathrm{mL}$ to $1.0 \mu \mathrm{g} / \mathrm{mL}$. Maximum adsorption capacity occurred at $1.0 \mu \mathrm{g} / \mathrm{ml}$ concentration which reached equilibrium after 36 hours at $1.7 \mu \mathrm{g} / \mathrm{g}$. Adsorption removal and adsorption capacity increased with increased of initial concentration. This value considerably low, indicated that polyethylene microbeads only have few sites available for adsorption. Thus, giving minimal associations of chromium with microbeads. Simultaneously with increased concentration of chromium in microbeads, the concentration in aqueous solution relatively decreased. Cr concentration increased significantly for all experiment until it reached equilibrium at maximum 144 hours for $0.2 \mu \mathrm{g} / \mathrm{ml}$ and 36 hours for $1.0 \mu \mathrm{g} / \mathrm{ml}$. This interaction was considered as relatively slow with respect to initial concentration.

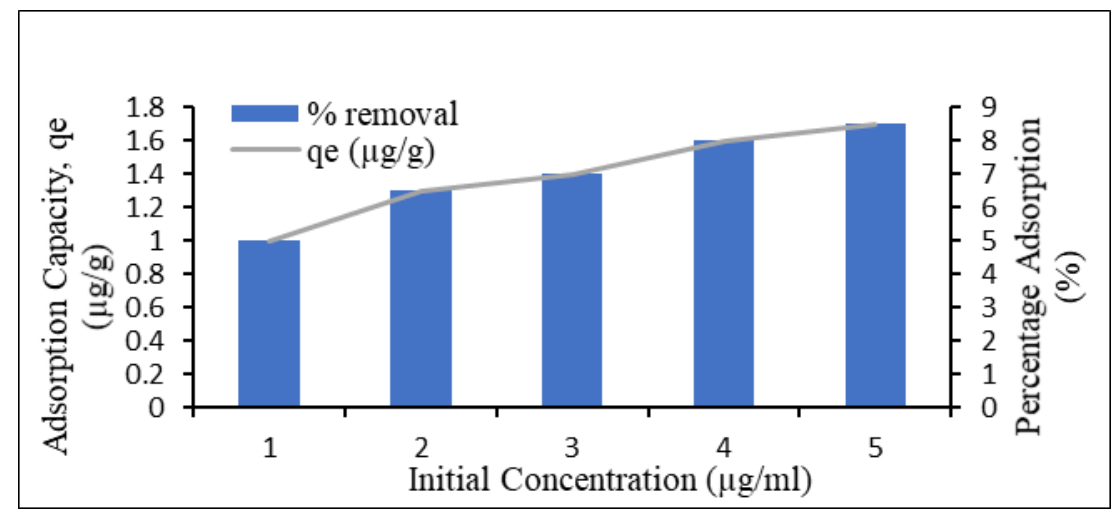

Fig. 1. Adsorption capacity and adsorption percentage which correspond to initial concentration of chromium.

The abundance of chromium in $1.0 \mu \mathrm{g} / \mathrm{ml}$ exposed to polyethylene microbeads higher than other concentration due to its high molecules availability in solution making it easier to interact to microbeads surface. The rate interaction of chromium-microbeads in term of kinetic is discussed further in kinetic adsorption study. The result might differ for different types of microbead-heavy metals combination. Adsorption occurrence was also determined based on its surface area and reactivity or affinity to specific heavy metals-plastic type [14]. 
Ashton and others also found that, the adsorption mechanism for metal adsorption might be because of direct adsorption of cations/anions or complexes onto charged sites or neutral region of plastic surface [4,17].

\subsection{Adsorption Kinetics}

Based on time dependency of chromium uptake by polyethylene microbeads profiles in Figure 2, the adsorption occurred is considered as rapid and subsequent approach to equilibrium or more protracted period of slower adsorption. The equilibrium attained at approximately 144 hours for $0.2 \mu \mathrm{g} / \mathrm{ml}$ of chromium and directly proportional at higher concentration. Polyethylene microbeads-chromium was relatively in good agreement for pseudo-first-order of kinetic and it was in good agreement to Holmes and colleagues in 2012 [14]. Rates of chromium-polyethylene microbeads was modelled using pseudo-firstorder reversible reaction [19].

$$
\log \left(q_{e}-q_{t}\right)=\log q_{e}-\frac{k_{m a d}}{22303} t
$$

Where $\mathrm{q}_{\mathrm{e}}$ represent as metal adsorbed to microbeads surface at equilibrium and $\mathrm{k}_{\mathrm{ad}}$ is rate constant. The equilibrium of chromium adsorption in this system was achieved at approximately 30 hours to 140 hours. Pseudo-first-order kinetic specified that desorption is possible in this adsorption type. Theoretically, the adsorption kinetic represents adsorption in multilayer and monolayer occurred with electrostatic, hydrogen bonds, van der waals or dipole-dipole [21]. The pseudo-first order kinetic of adsorption constants is summarized in Table 1.

Table 1. Comparison between different adsorbate (chromium) concentration and correlation coefficient associated with pseudo-first-order.

\begin{tabular}{|c|c|c|c|}
\hline Initial concentration Cr $(\mu \mathrm{g} / \mathrm{ml})$ & \multicolumn{3}{|c|}{ Pseudo-first-order rate equation } \\
\cline { 2 - 4 } & $\mathrm{K}_{\mathrm{ad}}\left(\right.$ hour $\left.^{-1}\right)$ & $\mathrm{q}_{\mathrm{e}}(\mu \mathrm{g} / \mathrm{g})$ & $\mathrm{r}^{2}$ \\
\hline 0.2 & 0.01680 & 1.6121 & 0.9034 \\
\hline 0.6 & 0.03592 & 1.7382 & 0.9567 \\
\hline 1.0 & 0.08912 & 1.7163 & 0.9789 \\
\hline
\end{tabular}

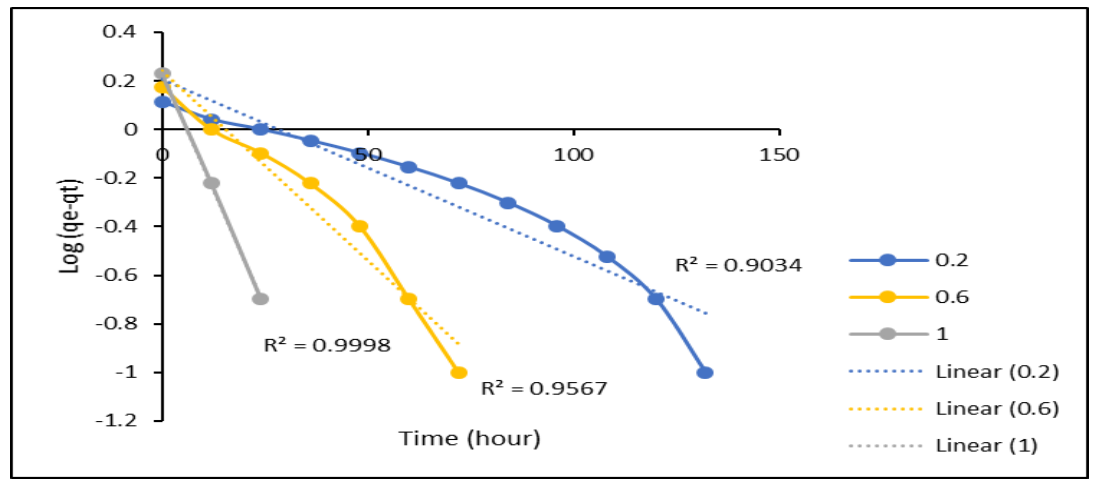

Fig. 2. Pseudo-first-order reaction for chromium adsorbed onto polyethylene microbeads at different initial concentration with different time equilibrium. 


\subsection{Adsorption Isotherm}

Isotherm defining the adsorption of chromium and polyethylene microbeads is shown in Figure 3 and Figure 4. Both Langmuir and Freundlich models were plotted and fitted to the isothermic. Langmuir model was assumed that maximum adsorption occurs when saturated monolayer chromium molecules is present on homogenous microbeads surface, the energy of adsorption is constant and there is no migration of chromium molecules in surface plane. The isotherm model was performed using linear regression analysis based on equation 2 and 3 .

$$
\begin{aligned}
& q_{a}=\frac{q_{m} K_{\mathbb{L}} C_{a}}{1+R_{\mathbb{l}} C_{m}} \\
& \frac{1}{q_{2}}=\frac{1}{q_{m}}+\frac{1}{q_{m} K_{L_{\text {T }}}^{C}}
\end{aligned}
$$

Where $\mathrm{q}_{\mathrm{e}}$ and $\mathrm{q}_{\mathrm{m}}$ represent maximum adsorption capacity for the microbeads loading and energy constant related to heat of adsorption respectively. Figure 3 fitted equation well with $\mathrm{r}^{2}=0.9707$. The value of $\mathrm{q}_{\mathrm{m}}$ and $\mathrm{K}_{\mathrm{L}}$ determined to be $1.9171 \mu \mathrm{g} / \mathrm{g}$ and $5.7193 \mu \mathrm{g} / \mathrm{ml}$ respectively.

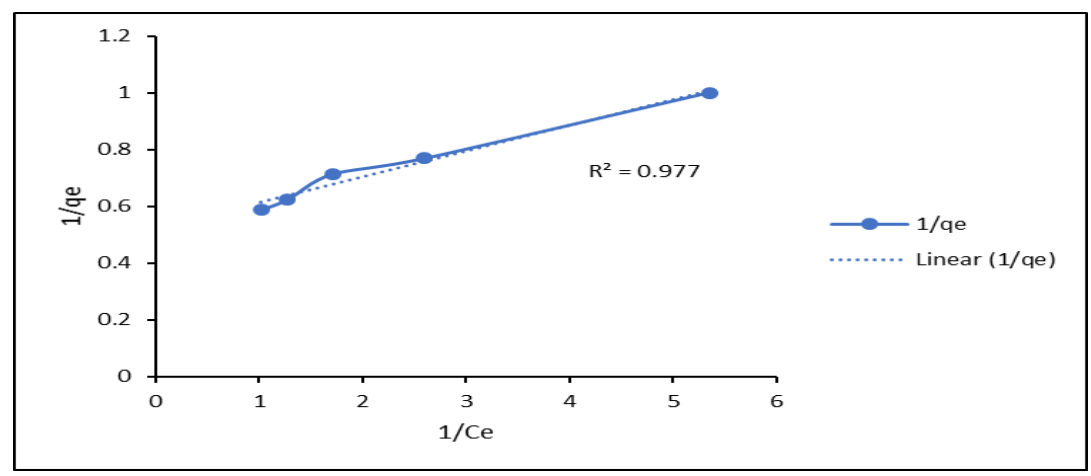

Fig. 3. Langmuir adsorption isotherm.

While Freundlich isotherm model described adsorption of chromium from solution to microbeads surface with assumptions different sites with several adsorption energies involved. The relationship of chromium adsorbed per unit mass of microbeads $\mathrm{q}_{\mathrm{e}}$ and the concentration of chromium at equilibrium $\mathrm{C}_{\mathrm{e}}$ with logarithmic equation as shown in equation 4 .

$$
\log q_{e}=\log K_{\mathrm{F}}+\frac{1}{n} \log C_{e}
$$

Where $\mathrm{K}_{\mathrm{F}}$ and $\mathrm{n}$ indicate as adsorption capacity and adsorption intensity respectively. The value was determined from graph at $1.6646 \mu \mathrm{g}^{1-1 / \mathrm{n}} \mathrm{g}^{-1}$ and 6.3051 . The values found for $\mathrm{K}_{\mathrm{F}}$ and $\mathrm{n}$ were higher than in Langmuir, represent more favourable adsorption occur despite of no information on monolayer adsorption capacity. The coefficient correlation was found to be 0.9606 . 


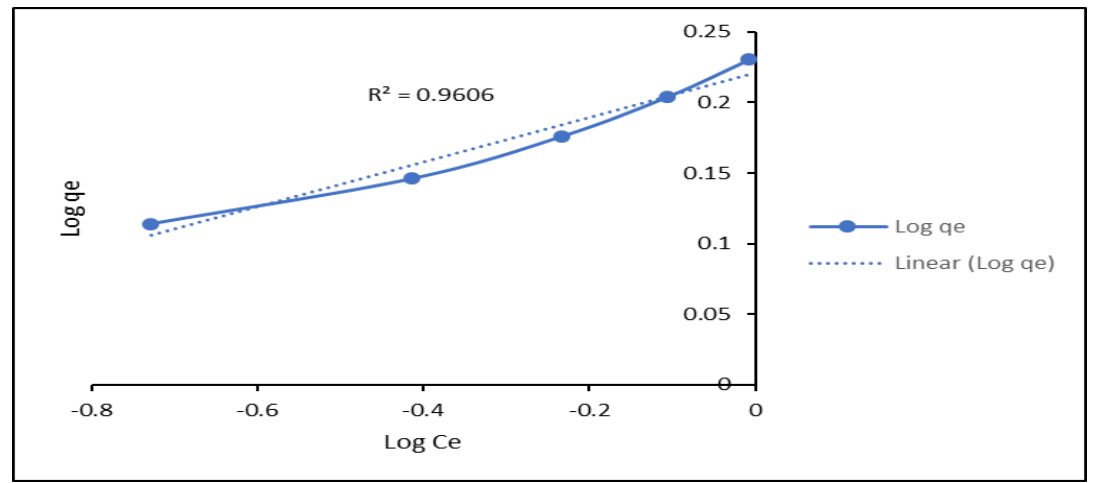

Fig. 4. Freundlich adsorption isotherm.

Table 2 represented adsorption constants corresponding isotherm of Langmuir and Freundlich correspondingly.

Table 2. Isotherm models constant and correlation coefficients for adsorption for adsorption chromium from aqueous solution.

\begin{tabular}{|l|c|c|c|c|c|}
\hline \multicolumn{3}{|c|}{ Freundlich } & \multicolumn{3}{c|}{ Langmuir } \\
\hline $\mathrm{r}^{2}$ & $\mathrm{n}$ & $\left.\begin{array}{c}1-1 / \mathrm{n}-1 \\
\mathrm{~K}(\mu \mathrm{g}\end{array}\right)$ & $\mathrm{r}^{2}$ & $\mathrm{~K}(\mu \mathrm{g} / \mathrm{ml})$ & $\mathrm{q}(\mu \mathrm{g} / \mathrm{g})$ \\
\hline 0.9606 & 6.3051 & 1.6646 & 0.977 & 5.7193 & 1.9171 \\
\hline
\end{tabular}

The different assumptions of the two isotherm models with different characteristic of polyethylene microbeads, there are no clear differences in the coefficient of determination to the data of experiment. Despite that, general assumption that plastics are inert to aqueous metals, polyethylene microbeads suspended in chromium-amended seawater rapidly and fitted in Langmuir and Freundlich models, it was presumed that, chromium adsorption occurred in through interaction between oxyanions $\left(\mathrm{Cr}_{2} \mathrm{O}_{4}^{2-}\right)$ with charged of imperfections or in presence of polyethylene microbeads additives. Non-specific interactions between neutral chromium-organic complexes and hydrophobic surface of the bulk plastic medium might take place in the interactions [14]. Low value of equilibrium partition coefficient indicated that, the contaminants in seawater was in mobility. Thus, kinetic adsorption which fitted pseudo-first order is in good agreement of the process.

Previous study for beached pellets equilibrium occurred at 25-100 hours [14]. However, other researchers claimed that, all types of plastic tend to accumulate with similar concentration of metals and increased over time without reaching saturation point [5]. From previous perspective, plastic particles were seen as an inert compared to heavy metals due to its impact to physical damage such as ingestion and entanglement rather than sources of contaminants carrier [17]. Duarte and colleagues found that, particles behaviour of adsorption is similar to estuarine sediments [18]. In this context, microbeads might enter the food chain since its behaviour is similar to estuarine sediment and also acted as a vector for heavy metals in environment [15].

\section{Conclusion}

Through investigation of batch experiment between chromium and microbeads under controlled laboratory conditions using low density polyethylene microbeads (MB) as a model plastic particle, it was revealed that interaction between chromium and surface 
polyethylene microbeads are occurred rapidly. However, the equilibrium constant might underestimate of environmental values [14]. Association of chromium and plastic is considered as general phenomena in term of aquatic environments with respect to different size and types of plastic.

Rate of adsorption depends on few factors that need to be considered such as surface area and reactivity of chromium to polyethylene microbeads particles. Based on our findings, it was concluded that, microbeads can sorb heavy metals and if the ingestion occurred to aquatic life, it will become a vector and an additional path for heavy metals to enter the food chain through ingestion. Further investigation needs to be considered in term of time of adsorption, specific microbeads-heavy metals combination and contaminated microbeads of heavy metals to aquatic organism.

\section{References}

1. D. Eerkes-Medrano, R.C. Thompson, D.C. Aldridge, Water Res. 75, 63-82 (2015)

2. G. Vandermeersch, L. Van Cauwenberghe, C.R. Janssen, A. Marques, K. Granby, G. Fait, M.JJ Kotterman, J. Diogene, K. Bekaert, J. Robbens, L. Devriese, Environ. Res. 143, 46-55 (2015)

3. J. R. Jambeck, R. Geyer, C. Wilcox, T.R. Siegler, M. Perryman, A. Andrady, R. Narayan, K. L. Law, Science 347, 768-771 (2015)

4. M. Cole, P. Lindeque, C. Halsband, T. S. Galloway, Mar. Pollut. Bull. 62, 2588-2597 (2011)

5. L. S. Fendall and M. A. Sewell, Mar. Pollut. Bull. 58, 1225-1228 (2009)

6. A. L. Andrady, Mar. Pollut. Bull. 62, 1596-1605 2011)

7. H. K. Imhof, N. P. Ivleva, J. Schmid, R. Niessner, C. Laforsch, Curr. Biol. 23, R867R868 (2017)

8. C. Alomar, A. Sureda, X. Capó, B. Guijarro, S. Tejada, S. Deudero, Environ. Res. 159, 135-142 (2017)

9. C. Boucher, M. Morin, L. I. Bendell, Reg. Stud. Mar. Sci. 3, 1-7 (2016)

10. S. Grigorakis, S. A. Mason, K. G. Drouillard, Chemosphere 169, 233-238 (2017)

11. A. Karami, D. B. Groman, S. P. Wilson, P. Ismail, V. K. Neela, Environ. Pollut. 223, 466-475 (2017)

12. G. Peng, P. Xu, B. Zhu, M. Bai, D. Li, Environ. Pollut. 234, 448-456 (2018)

13. M. F. M. Santana, L. G. Ascer, M. R. Custòdio, F. T. Moreira, A. Turra, Mar. Pollut. Bull. 106, 183-189 (2016)

14. L. A. Holmes, A. Turner, R. C. Thompson, Environ. Pollut. 160, 42-48 (2012)

15. D. Brennecke, B. Duarte, F. Paiva, I. Caçador, J. Canning-Clode, Estuar. Coast. Shelf Sci. 178, 189-195 (2016)

16. V. Hatje, T. E. Payne, D. M. Hill, G. Mcorist, G. F. Birch, R. Szymczak, “Env. Int. 29, 619-629 (2006)

17. K. Ashton, L. Holmes, A. Turner, Mar. Pollut. Bull. 60, 2050-2055 (2010)

18. B. Duarte, M. Caetano, P. R. Almeida, C. Vale, I. Caçador, Environ. Pollut. 158, 16611668 (2010)

19. A. Turner, M. Crussell, G. E. Millward, A. Cobelo-garcia, A. S. Fisher, Environ. Sci. Technol 40, 1524-1531 (2006) 
20. E. L. Teuten, S. J. Rowland, T. S. Galloway, R. C. Thompson, Environ. Sci. Technol. 41, 7759-7764 (2007)

21. C. P. Bergmann, F. M. Machado, Carbon Nanomaterials as Adsorbents for Environmental and Biological Applications (Springer, 2015) 